\title{
Unplanned Reoperation Following Gynaecological Surgeries
}

$$
\text { A report from Jordan }
$$

*Ismaiel Abu Mahfouz, ${ }^{1}$ Ibtehal Abu Shabab, ${ }^{2}$ Heba Abu Saleem, ${ }^{2}$ Salem Abu Mahfouz,,${ }^{3}$ Qasem Shehab, ${ }^{4}$ Fida Asali ${ }^{5}$

$$
\text { إعادة العمليات الجراحية غير المخطط لها بعد جراحات أمراض النساء }
$$

$$
\text { اسماعيل أبو محفوظ، ابتهال أبو شهاب، هبة أبو سليم، سالم أبو محفوظ، قاسم شهاب، فداء العسلي }
$$

ABSTRACT: Objectives: Unplanned return to the operating theatre refers to an unplanned reoperation following a primary surgical procedure and can result in serious complications. The rate of unplanned reoperations is often used as a measure of in-hospital quality monitoring and improvement. This study aimed to review the prevalence rate and features of unplanned gynaecological reoperations at a major general hospital in Jordan. Methods: This retrospective study took place between January 2011 and January 2018 at The Specialty Hospital in Amman, Jordan. The medical records of all women who underwent unplanned reoperations following a primary gynaecological procedure during this period were reviewed. Results: A total of 4,895 primary gynaecological procedures were performed during the study period, of which 4,175 (85.3\%) were elective and 720 (14.7\%) were emergency operations. There were 15 unplanned reoperations $(0.3 \%)$; of these, 14 (93.3\%) followed elective procedures and one (6.7\%) followed an emergency surgery. Most reoperations were performed following hysterectomies (53.3\%). Bleeding was the predominant reason for reoperation (93.3\%), with the source of the bleeding successfully identified in $71.3 \%$ of cases. In terms of outcome, none of the cases required a subsequent reoperation and there were no mortalities. Conclusion: The rate of unplanned reoperation at a hospital in Jordan was $0.3 \%$. Unplanned reoperations occurred primarily as a result of bleeding following hysterectomies. Development of care pathways may reduce surgical complications and rates of unplanned reoperation.

Keywords: Reoperation; Gynecology; Surgical Specialties; Intraoperative Complications; Hysterectomy; Clinical Audit; Jordan.

الملخص: الهدف: الرجوع غير المخطط له إلى غرفة العمليات يعرف بإعادة العملية الجراحية غير المخطط لها بعد العبات العملية الجراحية الأولية

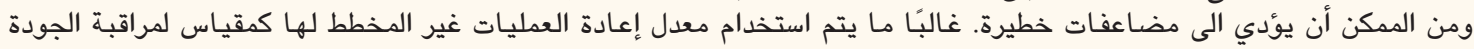

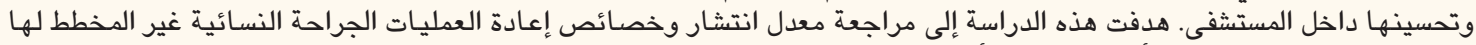

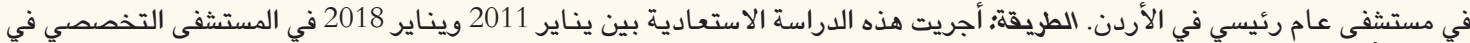

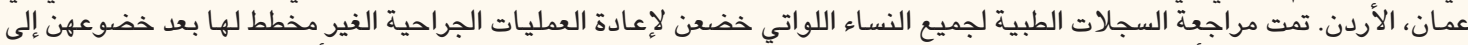

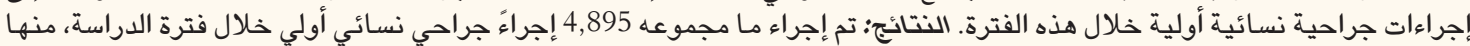

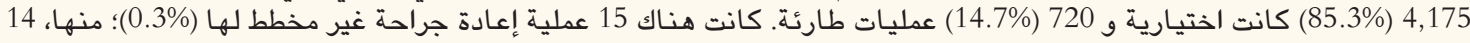

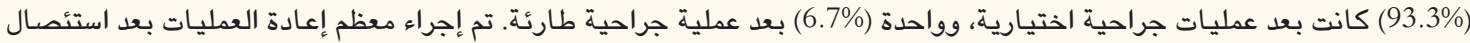

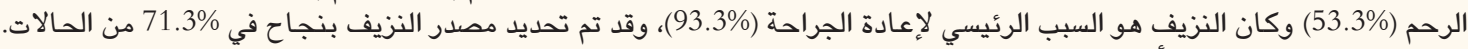

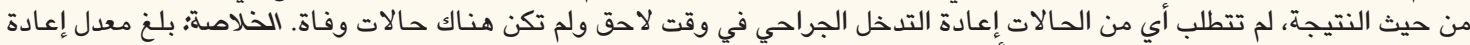

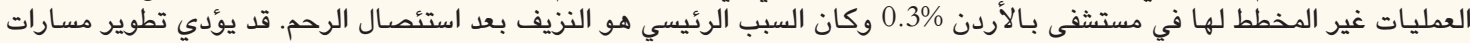
الرعاية إلى تقليل المضاعفات الجراحية ومعدلات إعادة العمليات الجراحية العبات الغير الغير مخطط لها.

الكلمات المفتاحية: إعادة العمليات الجراحية؛ طب النساء؛ التخصصات الجراحية؛ المضاعفات أثناء العملية؛ استئصسال الرحم؛ التدقيق السريري؛ الأردن.

\section{Advances In KNOWLEDGE}

Few reports have been published focusing on unplanned reoperations following gynaecological procedures compared to other surgical specialities. This study found that the rate of unplanned reoperations at a major general hospital in Jordan was $0.3 \%$.

Moreover, unplanned reoperations occurred primarily as a result of bleeding following hysterectomies.

\section{Application to Patient Care}

The findings of this study may encourage healthcare practitioners in Jordan to implement care pathways to reduce unplanned reoperation rates and encourage early recognition of gynaecological procedures likely to require an unplanned return to the operating theatre, thereby reducing associated morbidity and mortality rates. 
A CCORDING TO THE AMERICAN COLLEGE OF Obstetricians and Gynecologists, an unplanned reoperation is defined as a "return to the theatre due to complications or untoward outcomes related to the initial surgery". Between 1979 and 2006, 26.5\% of all inpatient surgical procedures performed for adult women in the USA were obstetrical or gynaecological in nature. ${ }^{2}$ While unplanned reoperations are rarely reported following gynaecological surgical operations, these procedures nevertheless carry the risk of morbidity and mortality. ${ }^{3}$ In addition, surgical complications and adverse events can occur despite the provision of appropriate perioperative care. $^{4-6}$

The rate of reoperation can be a useful marker for quality monitoring and improvement purposes. ${ }^{7}$ However, there is a paucity of research regarding reoperation rates in gynaecological procedures compared to other surgical specialties. To the best of the authors' knowledge, the most recent report regarding unplanned reoperations in gynaecology was published in 2011. ${ }^{8}$ As such, this study aimed to retrospectively review the rate of unplanned gynaecological reoperations at a major general hospital in Jordan, determine reasons and triggering factors for reoperation and identify specific procedures more likely to require an unplanned reoperation.

\section{Methods}

This retrospective study took place between January 2011 and January 2018 at the Gynecology \& Obstetrics Section of The Specialty Hospital in Amman, Jordan. This department provides general gynaecological services in addition to reproductive endocrinology, urogynaecology and gynaecology-oncology services. The medical records of all women who had undergone unplanned reoperations during the study period were identified from the hospital database. Women were only included in the study if they had received a primary gynaecological surgery as well as an unplanned reoperation within the same admission period.

Information was collected from the medical records including age, body mass index (BMI), the presence of comorbidities such as diabetes mellitus, hypertension or previous abdominal operations, type of primary surgical operation (i.e. the operation for which the woman was admitted) and whether it was an elective or emergency procedure, the cause of any unplanned reoperations and factors triggering the reoperation such as bleeding, changes in vital signs or a drop in haemoglobin $(\mathrm{Hb})$ level. In addition, data were recorded to determine length of time between identification of the complication and return to the operating theatre (OT), blood transfusion requirements, admission to the intensive care unit (ICU) and overall patient outcomes.

Data analysis was performed using the Statistical Package for the Social Sciences (SPSS), Version 22.0 (IBM Corp., Armonk, New York, USA). The results were presented using descriptive statistics. Means and standard deviations were reported for normally distributed and continuous variables. Ethical approval for this study was granted by the Institutional Review Board of The Specialty Hospital.

\section{Results}

Over the seven-year study period, a total of 4,895 primary gynaecological operations were performed including 4,175 (85.3\%) elective operations and 720 (14.7\%) emergency procedures. All procedures were performed for non-malignant pathologies. Moreover, $12.8 \%$ of the primary surgeries were minimal access procedures, comprising hysteroscopic (79.4\%) and laparoscopic (20.6\%) procedures [Table 1]. Overall, there were 15 unplanned reoperations (0.3\%) of which 14. (93.3\%) followed elective operations and one (6.7\%) followed an emergency operation. The mean age and BMI of the women requiring reoperation was $39.3 \pm$ 12.7 years and $24.6 \pm 3.8 \mathrm{~kg} / \mathrm{m}^{2}$, respecively. Moreover, $53.3 \%$ of the women had various comorbidities [Table 2].

All of the primary surgeries were performed by a consultant gynaecologist or by trainees under the direct supervision of a consultant. In addition, all reoperations were performed by consultants assisted by trainees. According to the operative notes for the women who underwent unplanned reoperations, the attending gynaecologists documented moderate degrees of adhesion between the uterus, ovaries and other pelvic organs in four of the abdominal hysterectomies. There were no other special remarks in the operation notes for the remaining cases.

Six women $(40 \%)$ had an unplanned reoperation following an abdominal hysterectomy, resulting in a surgery-specific reoperation rate of $0.9 \%$. In addition, two unplanned reoperations (13.3\%) followed a vaginal hysterectomy, with or without a concomitant anterior and/or posterior vaginal wall repair; as such, the surgery-specific reoperation rate was $0.7 \%$. The combined rate of unplanned reoperations after hysterectomies was $0.8 \%$. Furthermore, two unplanned reoperations (13.3\%) followed a cervical dilatation and curettage $(D \& C)$ procedure, resulting in a surgery-specific reoperation rate of $0.6 \%$. In addition, three cases $(20 \%)$ followed an anterior and posterior vaginal wall repair, with the reoperation rate after such procedures being $0.3 \%$. One case $(6.7 \%)$ followed an 
Table 1: Primary gynaecological surgeries performed over a seven-year period at The Specialty Hospital, Amman, Jordan $(\mathrm{N}=4,895)$

\begin{tabular}{|c|c|}
\hline Primary surgery & n (\%) \\
\hline Anterior and posterior vaginal wall repair & 1,191 (24.3) \\
\hline Laparotomy* & $987(20.2)$ \\
\hline Open myomectomy & $793(16.2)$ \\
\hline Abdominal hysterectomy & $650(13.3)$ \\
\hline Laparoscopy $^{\dagger}$ & $129(2.6)$ \\
\hline Hysteroscopy $^{\dagger}$ & $498(10.2)$ \\
\hline $\mathrm{D} \& \mathrm{C}$ & $350(7.2)$ \\
\hline Vaginal hysterectomy & $297(6.1)$ \\
\hline
\end{tabular}

Table 2: Comorbidities among women who underwent unplanned reoperations over a seven-year period at The Specialty Hospital, Amman, Jordan $(\mathrm{N}=15)$

$\begin{array}{lc}\text { Comorbidity } & \text { n (\%) } \\ \text { DM } & 1(6.7) \\ \text { HTN } & 1(6.7) \\ \text { DM and HTN } & 1(6.7) \\ \text { Previous abdominal surgery } & 4(26.7) \\ \text { DM and previous abdominal surgery } & 1(6.7) \\ \text { DM = diabetes mellitus; HTN = hypertension. } & \end{array}$

Table 3: Rate of reoperation according to primary gynaecological surgery over a seven-year period at The Specialty Hospital, Amman, Jordan ( $\mathrm{N}=15)$

\begin{tabular}{|c|c|c|}
\hline Surgery & n (\%) & $\begin{array}{c}\text { Rate of } \\
\text { reoperation" } \\
\text { in } \%\end{array}$ \\
\hline Abdominal hysterectomy & $6(40)$ & 0.9 \\
\hline Vaginal hysterectomy & $2(13.3)$ & 0.7 \\
\hline $\begin{array}{l}\text { Anterior and posterior } \\
\text { vaginal wall repair }\end{array}$ & $3(20)$ & 0.3 \\
\hline $\mathrm{D} \& \mathrm{C}$ & $2(13.3)$ & 0.6 \\
\hline Open myomectomy & $1(6.7)$ & 0.1 \\
\hline Marsupialisation of $\mathrm{BGA}^{\dagger}$ & $1(6.7)$ & - \\
\hline
\end{tabular}

$D E C=$ dilatation and curettage; $B G A=$ Bartholin's gland abscess.

"According to type of surgery; ${ }^{+}$The total number of patients who had marsupialisation was not determined.

open myomectomy, resulting in a surgery-specific reoperation rate of $0.1 \%$. The final case $(6.7 \%)$ followed marsupialisation of a Bartholin's gland abscess [Table 3]. None of the minimal access procedures were complicated by unplanned reoperations.

Regarding the reason for reoperation, 14 women (93.3\%) were reoperated due to surgical bleeding,
Table 4: Bleeding sites among women who underwent unplanned reoperations due to surgical bleeding over a sevenyear period at The Specialty Hospital, Amman, Jordan $(\mathrm{N}=14)$

$\begin{array}{lc}\text { Site } & \mathbf{n}(\%) \\ \text { Vaginal vault } & 2(14.3) \\ \text { Infundibulopelvic vascular pedicle } & 2(14.3) \\ \text { Vaginal wall" } & 3(21.4) \\ \text { Cervix } & 1(7.1) \\ \text { Subrectus space } & 1(7.1) \\ \text { Vulvar skin }{ }^{\dagger} & 1(7.1) \\ { }^{*} \text { Following anterior and posterior vaginal wall repair. }{ }^{\dagger} \text { Following marsupi- } \\ \text { alisation of a Bartholin's gland abscess. }\end{array}$

Table 5: Triggering factor for reoperation among women who underwent unplanned reoperations over a seven-year period at The Specialty Hospital, Amman, Jordan ( $\mathrm{N}=15)$

$\begin{array}{lc}\text { Factor } & \mathbf{n}(\%) \\ \text { Vaginal bleeding } & 8(53.3) \\ \text { Drop in } \mathrm{Hb} & 3(21.4) \\ \begin{array}{l}\text { Abdominal pain, drop in } \mathrm{Hb} \text { and change } \\ \text { in vital signs }\end{array} & 3(21.4) \\ \text { Loin pain and hydronephrosis* } & 1(7.1)\end{array}$

$H b=$ haemoglobin. "As visualised using ultrasonography.

while one woman (6.7\%) was reoperated because of a right-sided ureteral injury. For those who underwent reoperation due to bleeding, the site of the bleeding was successfully identified in 10 cases (71.4\%) [Table 4]. No bleeding site was identified in the remaining four cases (28.6\%). For the remaining case, investigation of postoperative right-sided hydronephrosis by cystourethroscopy and retrograde pyelography revealed a right-sided ureteral injury.

Vaginal bleeding was the triggering factor for reoperation in $53.3 \%$ of cases; other triggers included decreases in $\mathrm{Hb}$ concentration, changes in blood pressure and heart rate suggestive of hypovolaemia and abdominal and loin pain followed by a renal ultrasound showing hydronephrosis [Table 5]. The mean drop in Hb was $3.3 \pm 1.2 \mathrm{~g} / \mathrm{dL}$ (range: $2-5 \mathrm{~g} / \mathrm{dL}$ ).

The mean time interval between the primary operation and reoperation was $12.3 \pm 8.3$ hours. The reoperations occurred in $<6$ hours in four cases (26.7\%), 6-12 hours in five cases (33\%), and 12-24 hours in seven cases (46.7\%). Moreover, 11 women (73.3\%) required transfusions of blood or blood components, with a mean of $2.7 \pm 2$ units transfused. In addition, three women (20\%) required overnight admission to the ICU. None of the women required further reoperations and all were discharged in good health. No mortalities were reported following any of the reoperations. 


\section{Discussion}

Reporting and analysing adverse events may improve standards of care for surgical patients..$^{9}$ In the current study, the rate of unplanned reoperations was $0.3 \%$ among gynaecological surgeries conducted over a seven-year period. Similar rates have been reported in other studies (0.03\%). ${ }^{8,10}$ A study by Dierks et al. indicated that $11 \%$ of unplanned reoperations were gynaecological in nature; moreover, the researchers noted that unplanned reoperations were underreported for various reasons including lack of agreement over what constituted an adverse surgical outcome, confusion regarding the goal or objective of reporting and lack of clarity over who should report it. In addition, medical staff may choose not to report poor surgical outcomes for various reasons which may include fear of stigma or litigation. ${ }^{11}$

In the present study, the vast majority (93.3\%) of unplanned reoperations occurred following elective procedures. This is consistent with findings reported by Mahfouz et al. in a previous retrospective review of primary gynaecological procedures. ${ }^{8}$ In contrast, Guevara et al. found that patients who underwent general emergency surgeries were more likely to have an unplanned reoperation compared to patients who had elective procedures. ${ }^{12}$ This difference is likely related to variations between gynaecological and general surgical populations.

More than half of the unplanned reoperations in the current study (53.3\%) occurred following a hysterectomy, with the rate of unplanned reoperations for this type of surgery being $0.8 \%$. Hysterectomies remain a very common gynaecological operation worldwide and are usually performed for benign reasons. ${ }^{13,14}$ Lambaudie et al. reported a comparable overall reoperation rate after a hysterectomy $(0.8 \%)$ with rates of perioperative bladder, ureteral and intestinal injuries being $0.9 \%, 0.06 \%$ and $0.6 \%$, respectively; moreover, excessive bleeding (i.e. blood loss of $>500 \mathrm{~mL}$ ) was reported in $2.8 \%$ of women. ${ }^{14}$

Vaginal wall repair for pelvic organ prolapse accounted for $24.3 \%$ of all primary gynaecological surgical procedures performed in the present study. The unplanned reoperation rate for this surgery was $0.3 \%$, with the cause of reoperation being bleeding in all three cases. Serious complications after pelvic floor repair are rare; Fritel et al. reported that only 2.8\% of women who underwent surgery for pelvic floor dysfunction sustained a serious complication either during surgery or in the early postoperative period. ${ }^{15}$

In the present study, $13.3 \%$ of unplanned reoperations occurred following a $\mathrm{D} \& \mathrm{C}$ procedure, with a surgery-specific unplanned reoperation rate of $0.6 \%$. In the first case, intraoprative findings identified cervical bleeding caused by trauma during instrumentation, while no bleeding site was identified in the second case. The high rate of unplanned reoperation after a relatively minor procedure such as a D\&C may be due to hospital practices of allowing junior doctors to perform these procedure with minimal direct supervision. In addition, the failure to identify a bleeding site in the second case may have been because the bleeding originated from the uterus and was not related to direct injury from the instruments. Postoperative haemorrhage is a recognised complication after a $\mathrm{D} \& \mathrm{C}$ with a prevalence rate of $0.05-4.9 \%{ }^{16}$ However, severe bleeding may indicate other causes such as a pseudo-aneurysm. ${ }^{17}$

The only emergency procedure in the present study which was complicated by an unplanned return to the OT was a case involving marsupialisation of Bartholin's gland abscess, in which bleeding was the cause for the reoperation. Marzano and Haefner reported that a Bartholin's cyst or abscess accounted for $2 \%$ of all gynaecological consultations. ${ }^{18}$ However, while marsupialisation procedures may be complicated by haemorrhage, there are no published reports regarding the rate of unplanned reoperation for haemorrhage following marsupialisation. ${ }^{19}$

In contrast, none of the minimal access procedures in the current study were followed by unplanned reoperations. This may be because the majority of such procedures were diagnostic in nature and performed by consultants. Alternatively, as these surgeries are often performed on an outpatient basis, some women requiring reoperation may have presented to other institutions. Naveiro Fuentes et al. reported that 1.93\% of 2,888 gynaecological endoscopic surgeries resulted in major complications, with seven cases of bowel perforation identified postoperatively. ${ }^{20}$

Reactionary bleeding refers to bleeding which occurs within the first 24 hours of surgery. ${ }^{21}$ This was the most common cause of unplanned reoperations in the current study, accounting for $93.3 \%$ of all cases. A previous retrospective review of unplanned reoperations in primary gynaecological procedures showed a similarly high percentage (100\%). ${ }^{8}$ Fortunately, all cases of bleeding in the present cohort were successfully controlled following the first reoperation. In contrast, Ashton et al. found that $0.45 \%$ of patients may require more than one reoperation to control reactionary bleeding. ${ }^{22}$

Unplanned reoperations may be necessary as a result of damage to organs near the operating field such as injuries to the bowel or urinary tract, with clinical presentation varying according to the organ involved. ${ }^{13}$ In the current study, the incidence of 
ureteral injuries following an abdominal hysterectomy was $0.2 \%$. Another study reported a comparatively low incidence of $0.35 \% .{ }^{23}$ In the present study, one woman (7.1\%) had a right-sided ureteral injury following an abdominal hysterectomy and underwent a right salpingo-oophorectomy performed for abnormal uterine bleeding, revealing a $10 \times 10 \mathrm{~cm}$ ovarian mass. The patient subsequently underwent a successful ureteral resection with end-to-end anastomosis. Tijani et al. reported that gynaecological operations account for up to $70 \%$ of iatrogenic ureteral injuries. ${ }^{24}$

Vaginal bleeding from the vaginal vault, walls or cervix was the triggering factor for reoperation in over $50 \%$ of cases in the current study. In these cases, the bleeding was overt and was immediately brought to the attention of the medical staff. However, cases of intra-abdominal and subrectus bleeding were less obvious and it was the changes in vital signs and drop in $\mathrm{Hb}$ levels which eventually raised the suspicion of internal bleeding. Therefore, no single factor should be considered in the evaluation of possible reactionary bleeding; clinical presentation, changes in vital signs and drop in $\mathrm{Hb}$ concentration should all be considered. ${ }^{8}$ Chamsy et al. proposed that routine postoperative testing of $\mathrm{Hb}$ levels had little clinical benefit when planning postoperative care following a laparoscopic hysterectomy; instead, the researchers suggested that this be reserved for women with clinical signs suggestive of acute blood loss. ${ }^{25}$

All of the women in the present study returned to the OT for an unplanned reoperation within the first 24 hours of the primary procedure, with almost $60 \%$ returning in 12 hours or less. This rapid turnaround time reflects prompt recognition and intervention of potential surgical complications; furthermore, there were no fatalities following any of the unplanned reoperations. Overall, mortality rates from gynaecological surgeries are extremely low; a retrospective study of 4,614 gynaecological procedures over a 10 -year period recorded 14 deaths, resulting in a mortality rate of $0.3 \% .^{2}$ Prompt recognition and timely resuscitation can reduce the mortality associated with serious surgical complications. ${ }^{26}$

In the present study, all of the primary surgical procedures were performed by a consultant or by a trainee under the direct supervision by a consultant, while all reoperations were performed by a consultant assisted by trainees. The presence of resident doctors alongside consultants in the OT during primary surgical procedures did not seem to affect the subsequent rate of unplanned reoperation. A recent meta-analysis similarly showed that the involvement of resident doctors in obstetrics and gynaecology surgery was not associated with increased risks of injury to adjacent organs, unplanned returns to the OT or wound infection rates. ${ }^{27}$

Setting standards of care in gynaecology has been shown to improve patient outcomes, with responsibility for this task usually falling to international professional organisations such as the Royal College of Obstetricians and Gynaecologists. ${ }^{28-30}$ Furthermore, cases of unplanned reoperation should be reviewed by a departmental committee and discussed in morbidity and mortality meetings in order to provide doctors and surgeons with the opportunity to learn from these adverse events. Ideally, the findings of the current study will encourage hospital policy-makers to implement special care pathways for surgical procedures such as hysterectomies which were associated with a higher incidence of unplanned reoperations. Such care pathways may include preoperative evaluation and the perioperative involvement of additional senior gynaecologists if the surgery proves difficult. In addition, additional postoperative care may help to increase early recognition and prompt intervention of surgical complications, thereby reducing morbidity and mortality.

Certain limitations of this study need to be acknowledged including the retrospective nature of the study design, relatively low numbers of unplanned reoperation cases and the fact that the data were sourced from a single hospital. These factors limit the generalisability of the results. Moreover, most endoscopic procedures are performed on an outpatient basis following discharge from hospital; as such, some women may have had complications necessitating a return to the OT and were admitted to another hospital. However, analysis of the complications following minimal access procedures was outside the scope of the present study.

\section{Conclusion}

The rate of unplanned reoperation in the current study was $0.3 \%$, with bleeding being the most common cause of reoperation. Certain surgical procedures such as hysterectomies were associated with a higher incidence of unplanned reoperations. However, no mortalities were reported following unplanned reoperation, likely as a result of the early recognition of complications and rapid re-intervention. The development of special care pathways for procedures which carry a higher risk of unplanned reoperation may reduce surgical complications and the rate of unplanned reoperations.

\section{CONFLICT OF INTEREST}

The authors declare no conflicts of interest. 


\section{FUNDING}

No funding was received for this study.

\section{References}

1. American College of Obstetrics and Gynaecologists. Quality Improvement in Women's Health Care, 2nd ed. Washington DC, USA: American College of Obstetrics and Gynaecologists, 2000.

2. Oliphant SS, Jones KA, Wang L, Bunker CH, Lowder JL. Trends over time with commonly performed obstetric and gynecologic inpatient procedures. Obstet Gynecol 2010; 116:926-31. https://doi.org/10.1097/AOG.0b013e3181f38599.

3. Gómez García MT, Fuentes Rozalén AM, del Cerro EL, Selva RM, Diana CS, Rodríguez CC, et al. Analysis of mortality associated with gynecological surgery between 2000 and 2010 at the General Hospital of Albacete, Spain. J Gynecol Surg 2011; 32:43-50. https://doi.org/10.1089/gyn.2015.0028.

4. Sokol DK, Wilson J. What is a surgical complication? World J Surg 2008; 32:942-4. https://doi.org/10.1007/s00268-0089471-6

5. Aspden P, Wolcott J, Bootman J, Cronenwett L, Eds. Preventing Medication Errors: Quality chasm series. Washington DC, USA: National Academies Press, 2007.

6. Croissant K, Shafi MI. Preoperative and postoperative care in gynaecology. Obstet Gynaecol Reprod Med 2009; 19:68-74. https://doi.org/10.1016/j.ogrm.2008.11.007.

7. Birkmeyer JD, Hamby LS, Birkmeyer CM, Decker MV, Karon NM, Dow RW. Is unplanned return to the operating room a useful quality indicator in general surgery? Arch Surg 2001; 136:405-11. https://doi.org/10.1001/archsurg.136.4.405.

8. Mahfouz I, Asali F, Wiltshire R, Sayer TR, Phillips $\mathrm{CH}$ Unplanned return to the operating theatre in gynaecology: Five years' experience. Eur J Obstet Gynecol Reprod Biol 2011; 157:222-5. https://doi.org/10.1016/j.ejogrb.2011.03.019.

9. Chung KC, Kotsis SV. Complications in surgery: Root cause analysis and preventive measures. Plast Reconstr Surg 2012; 129:1421-7. https://doi.org/10.1097/PRS.0b013e31824ecda0.

10. Connolly TP. Unplanned return to operating room in a community hospital-based obstetrics and gynecology residency. J Am Osteopath Assoc 2003; 103:123-5.

11. Dierks MM, Huang ZS, Siracuse JJ, Tolchin S, Moorman DW. Diagnostic, surgical judgment, and systems issues leading to reoperation: Mining administrative databases. Am J Surg 2010; 199:324-9. https://doi.org/10.1016/j.amjsurg.2009.09.020

12. Guevara OA, Rubio-Romero JA, Ruiz-Parra AI. Unplanned reoperations: Is emergency surgery a risk factor? A cohort study. J Surg Res 2013; 182:11-16. https://doi.org/10.1016/j. jss.2012.07.060.

13. Clayton RD. Hysterectomy. Best Pract Res Clin Obstet Gynaecol 2006; 20:73-87. https://doi.org/10.1016/j.bpobgyn.2005.09.007.

14. Lambaudie E, Boukerrou M, Cosson M, Querleu D, Crépin G. [Hysterectomy for benign lesions: Perioperative and early postoperative complications]. Ann Chir 2000; 125:340-5. https:// doi.org/10.1016/s0003-3944(00)00205-4.
15. Fritel X, Campagne-Loiseau S, Cosson M, Ferry P, Saussine C, Lucot JP, et al. Complications after pelvic floor repair surgery (with and without mesh): Short-term incidence after 1873 inclusions in the French VIGI-MESH registry. BJOG 2020; 127:88-97. https://doi.org/10.1111/1471-0528.15956.

16. Kwon JH, Kim GS. Obstetric iatrogenic arterial injuries of the uterus: Diagnosis with US and treatment with transcatheter arterial embolization. Radiographics 2002; 22:35-46. https:// doi.org/10.1148/radiographics.22.1.g02ja0735.

17. Kim YA, Han YH, Jun KC, Jeon MK, Lee ES. Uterine artery pseudoaneurysm manifesting delayed postabortal bleeding. Fertil Steril 2008; 90:849.e11-4. https://doi.org/10.1016/j. fertnstert.2007.07.1372.

18. Marzano DA, Haefner HK. The Bartholin gland cyst: Past, present, and future. J Low Genit Tract Dis 2004; 8:195-204. https://doi.org/10.1097/00128360-200407000-00006.

19. Lee WA, Wittler M. Bartholin gland cyst. In: StatPearls. Treasure Island, Florida, USA: StatPearls Publishing, 2019.

20. Naveiro Fuentes M, Rodríguez-Oliver A, Naveiro Rilo JC, González Paredes A, Aguilar Romero MT, Fernández Parra J. Complications of laparoscopic gynecologic surgery. JSLS 2014; 18:e2014.00058. https://doi.org/10.4293/JSLS.2014.00058.

21. Erian M, McLaren G, Khalil A. Reactionary hemorrhage in gynecological surgery. JSLS 2008; 12:81-4.

22. Ashton P, Beischer N, Cullen J, Ratten G. Return to theatre: Experience at the Mercy Maternity Hospital, Melbourne 19711982. Aust N Z J Obstet Gynaecol 1985; 25:159-69. https://doi. org/10.1111/j.1479-828x.1985.tb00635.x.

23. Liapis A, Bakas P, Giannopoulos V, Creatsas G. Ureteral injuries during gynecological surgery. Int Urogynecol J 2001; 12:391-3. https://doi.org/10.1007/PL00004045.

24. Tijani KH, Onwuzurigbo KI, Ojewola RW, Afolabi BB, Akanmu NO. Iatrogenic ureteric injuries in a Nigerian teaching hospital: Experience in the last decade. East Afr Med J 2011; 88:304-9.

25. Chamsy DJ, Louie MY, Lum DA, Phelps AL, Mansuria SM. Clinical utility of postoperative hemoglobin level testing following total laparoscopic hysterectomy. Am J Obstet Gynecol 2014; 211:224.e1-7. https://doi.org/10.1016/j.ajog.2014.04.003.

26. Almoudaris AM, Burns EM, Mamidanna R, Bottle A, Aylin P, Vincent $C$, et al. Value of failure to rescue as a marker of the standard of care following reoperation for complications after colorectal resection. Br J Surg 2011; 98:1775-83. https://doi. org/10.1002/bjs.7648.

27. Bougie O, Zuckerman SL, Switzer N, How J, Sey M. Influence of resident involvement in obstetrics and gynaecology surgery on surgical outcomes: Systematic review and metaanalysis. J Obstet Gynaecol Can 2018; 40:1170-7. https://doi. org/10.1016/j.jogc.2017.10.035.

28. O'Dowd M. Standards for gynecologic surgery. J Obstet Gynaecol India 2013; 63:7-13. https://doi.org/10.1007/s13224013-0405-3.

29. Haynes AB, Weiser TG, Berry WR, Lipsitz SR, Breizat AH, Dellinger EP, et al. A surgical safety checklist to reduce morbidity and mortality in a global population.N Engl J Med 2009; 360:491-9. https://doi.org/10.1056/NEJMsa0810119.

30. Royal College of Obstetricians and Gynaecologists. RCOG strategy. From: www.rcog.org.uk/en/about-us/what-we-do/ rcog-strategy/ Accessed: Apr 2020. 